\title{
Allergic conditions are not associated with the risk of non-Hodgkin's lymphoma or Hodgkin's lymphoma: a systematic review and meta-analysis
}

This article was published in the following Dove Press journal:

OncoTargets and Therapy

18 April 2017

Number of times this article has been viewed

\author{
Jia Yang \\ Hong'en Xu \\ Xiaodong Liang \\ Shiliang Lv \\ Baihua Lin \\ Yongshi Jia
}

Department of Radiotherapy,

Zhejiang Provincial People's Hospital,

Hangzhou, People's Republic of China
Correspondence: Yongshi Jia

Department of Radiotherapy, Zhejiang

Provincial People's Hospital, I58

Shangtang Road, Hangzhou 310014 ,

People's Republic of China

Tel/fax +86 57I 85893638

Email dryongshijia@163.com
Abstract: We aimed to systematically evaluate the association between allergic conditions and the risk of Hodgkin's lymphoma (HL) and non-HL (NHL). Systematic literature searches in PubMed and Embase were conducted up to October 2015 to identify eligible studies. Either a fixed-effects model or a random-effects model was adopted to estimate overall odds ratios (ORs) according to heterogeneity across studies. Subgroup and publication bias analyses were applied. A total of 24 case-control studies and 13 cohort studies (conducted from 1987 to 2015) were included in the analysis of the risk of NHL. History of any allergic condition was inversely associated with the risk of NHL in case-control studies ( $\mathrm{OR}=0.83,95 \% \mathrm{CI} 0.76-0.91)$, while the reduction in the risk of NHL was not observed in cohort studies ( $\mathrm{OR}=1.18,95 \%$ CI 0.98-1.42). Significant association with the risk of NHL was found for asthma, hay fever, food allergy, allergic rhinitis, and hives. In the pooled analysis of the risk of HL, 12 studies (two were cohort studies) were included. The pooled OR was 0.96 (95\% CI 0.84-1.09) for case-control studies and 1.46 (95\% CI 0.63-3.38) for cohort studies. For specific allergic condition, we observed a reduced risk of HL in individuals with hay fever and food allergy. In conclusion, history of any allergic condition was not significantly associated with the risk of NHL or HL. Several specific allergic conditions, including asthma, hay fever, food allergy, and allergic rhinitis, might be associated with a reduced risk of NHL, while individuals with hay fever or food allergy may have a reduced risk of HL.

Keywords: allergic condition, non-Hodgkin's lymphoma, Hodgkin's lymphoma, risk

\section{Introduction}

Lymphomas represent a group of heterogeneous malignancies, which are the sixth most common cancer in men and fifth most common cancer among women. ${ }^{1}$ Previous epidemiological studies have suggested significant association between lymphoma and severe immune deficiencies (such as primary and acquired immunodeficiency diseases and organ transplantation). ${ }^{2,3}$ For organ transplantation, an increased risk of non-Hodgkin's lymphoma (NHL) and abnormal proliferation of lymphocytes were observed, possibly because of the antigenic stimulation by the transplanted organ and the immunosuppressive therapy. Moreover, the origin of NHL was from cells of the immune system. ${ }^{4}$ Allergic conditions, such as asthma, hay fever, and allergic dermatitis, are characterized by immediate hypersensitivity reactions to environmental allergens and may indicate a heightened immune system, which may contribute to recognition and removal of malignant cells and thus reduce the risk of cancer. Thus, it is plausible that allergic conditions are also associated with the risk of lymphomas. In contrast, antigenic stimulation may lead to a chronic inflammation and stimulate cell growth, which may increase the risk of malignancies. ${ }^{5}$ 
There has long been interest in the association between allergic conditions and the risk of lymphoma. Several casecontrol studies have indicated that people with a history of allergic conditions might have a lower risk of NHL. ${ }^{6-8}$ In a meta-analysis of 13 case-control studies, allergic conditions, such as hay fever and asthma, were observed to be modestly associated with the risk of NHL. ${ }^{9}$ However, results from cohort studies are inconsistent, ${ }^{10-12}$ as evidence from cohort studies is generally considered to be stronger than that from retrospective studies; a meta-analysis including both case-control studies and cohort studies might be warranted. Moreover, no meta-analysis has been conducted to assess the association between allergic conditions and the risk of Hodgkin's lymphoma (HL) in general population.

Thus, we performed this systematic review and metaanalysis to further clarify the association between allergic conditions and the risk of NHL/HL.

\section{Methods}

\section{Literature search and study selection}

This systematic review and meta-analysis was planned, conducted, and reported according to the PRISMA statement. ${ }^{13}$ A systematic literature search was conducted in the PubMed and Embase databases without restrictions (up to October 2015). The following terms were used in the search procedure: ("allergies" OR "allergy" OR "allergic" OR "atopy" OR "atopic" OR "asthma" OR "allergic rhinitis" OR "hay fever" OR "atopic dermatitis" OR "hive" OR "eczema") AND lymphoma. We also scanned the reference lists of relevant articles and reviews to avoid missing studies. The retrieved articles were carefully examined to exclude duplicated studies. Titles and abstracts of the articles retrieved from the literature search were first scanned, and then, full articles were reviewed for those potentially eligible studies.

Two investigators independently evaluated the eligibility of studies for inclusion. Studies were eligible for inclusion if all the following criteria were fulfilled: 1) the study should be cohort or case-control, 2) the study should assess the association between allergic conditions and the risk of lymphoma, 3) the study should report the risk estimate as an odds ratio (OR), relative risk (RR), hazard ratio (HR), or standardized incidence ratio (SIR) with $95 \%$ confidence interval (CI). If data were reported in two or more studies, the most detailed one should be included.

\section{Data extraction}

Two authors independently performed data extraction with standardized forms, and any discrepancy was resolved by discussion or by a third investigator. The following information was extracted from each study: first author and publication year, study design, country of origin, age and gender of the participants, numbers of participants and lymphoma cases, variables adjusted for in the analysis, and OR (RR or HR) estimates with 95\% CIs for the risk of NHL/HL. For studies that reported both adjusted ratios and crude ratios, ratios reflecting the greatest degree of control for potential confounders were adopted in the meta-analysis.

\section{Statistical analysis}

The extent of heterogeneity across the included studies was evaluated by the chi-square test and $I^{2}$ test; $P \leq 0.05$ and $I^{2}>50 \%$ were defined as significant heterogeneity. ${ }^{14}$ Studyspecific effect estimates were pooled using a random-effects model if there was significant heterogeneity, otherwise a fixed-effects model was applied. We first assessed the association between history of any allergic condition and the risk of NHL and HL. Subgroup analyses for the risk of NHL and HL were then performed, stratifying by study design, type of allergic conditions, type of lymphoma, and country of origin. When heterogeneity across studies was significant, subgroup analyses were used to explore the source. Begg's funnel plots and Egger's linear regression method were used to evaluate the risk of publication bias. Twosided $P$-values were calculated, and $P<0.05$ was defined as significant for all the tests. All analyses were performed using the Stata software (Version 11.0; StataCorp, College Station, TX, USA).

\section{Results}

\section{Description of the included studies}

The systematic literature search of PubMed and Embase databases resulted in the identification of 2,875 articles, of which 81 were potentially eligible. Among these articles, 40 were excluded for the following reasons: did not report the association between allergic conditions and the risk of lymphoma $(n=24)$, not original articles $(n=5)$, insufficient data $(n=6)$, and duplicate reports from the same study population $(n=5)$. A total of 41 articles were finally included in the present meta-analysis, ${ }^{2,4,6-8,10-12,15-47}$ as shown in Figure 1.

The characteristics of the included studies are presented in Table S1. Among the included studies, 37 studies reported the association between allergic conditions and the risk of NHL, 2,4,6-8,10-12,16-18,20-23,25,27-47 while 12 studies investigated the risk of HL (several studies reported both NHL and HL). 2,7,10,15, 19,24,26,27,29,32,33,39 


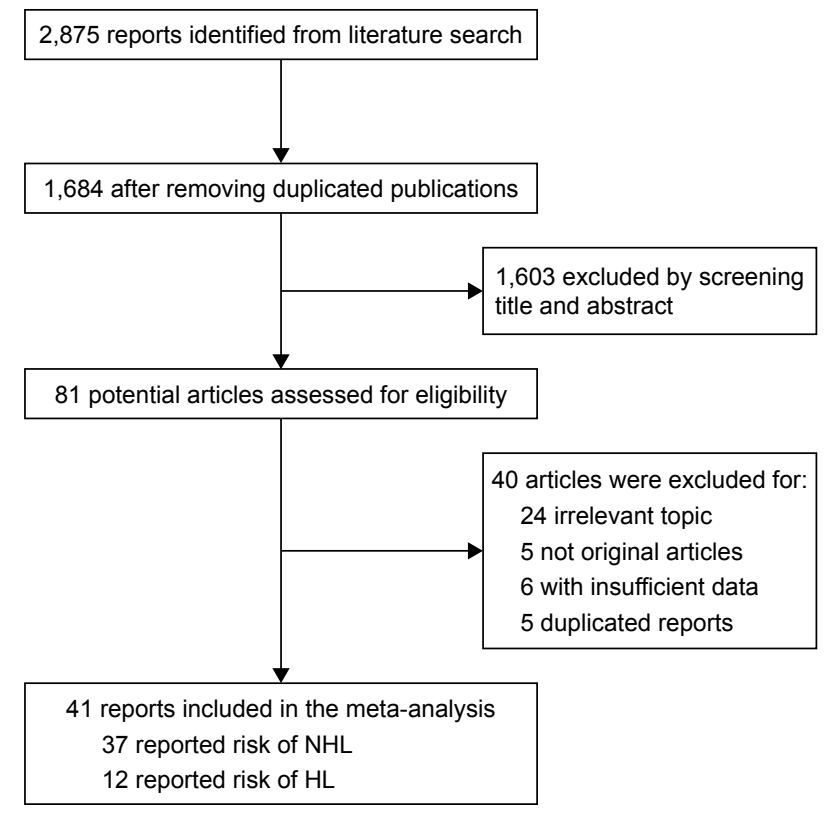

Figure I Flow diagram of the selection process.

Note: Several studies assessed the risk of both NHL and HL.

Abbreviations: NHL, non-Hodgkin lymphoma; HL, Hodgkin lymphoma.

\section{Association between allergic conditions and the risk of $\mathrm{NHL}$}

A total of 37 articles evaluated the association between allergic conditions and the risk of NHL. Among these studies, 24 were case-control studies including 35725 NHL patients (15 population based and 9 hospital based), while 13 were cohort studies (nine prospective and four retrospective) that comprised 4452 NHL patients. Two studies enrolled only female participants, and three studies included only males, while the other studies assessed the risk of NHL in both males and females. Most of the included studies were conducted in North America (USA and Canada) and European countries, while one study was performed in China and another in Australia.

We observed a significant difference between casecontrol studies and cohort studies. The pooled analysis of the 24 case-control studies resulted in an OR of $0.83(95 \%$ CI $0.76-0.91)$ with significant heterogeneity $\left(I^{2}=66.7 \%\right.$, $P<0.001)$, indicating an inverse association between history of any allergic condition and the risk of NHL (Figure 2A and Table 1). The reduction in the risk of NHL was found in population-based case-control studies (pooled $\mathrm{OR}=0.80$, 95\% CI 0.73-0.88) but not in hospital-based case-control studies (pooled OR $=0.90,95 \%$ CI 0.71-1.13) (Figure 2A and Table 1). There was no significant association between allergic conditions and the risk of NHL in cohort studies (pooled OR $=1.18,95 \%$ CI $0.98-1.42)\left(I^{2}=88.7 \%, P<0.001\right)$
(Figure 2B and Table 1). Null associations were found both in prospective cohorts (pooled OR $=1.05,95 \%$ CI $0.86-1.28$ ) and in retrospective cohorts (pooled $\mathrm{OR}=1.54,95 \% \mathrm{CI}$ 0.91-2.58) (Figure 2B and Table 1). The pooled analysis of all the 37 included studies represented an OR of 0.93 (95\% CI 0.84-1.04) $\left(I^{2}=87.8 \%, P<0.001\right)$ (Table 1).

Subgroup analyses were also conducted for specific allergic condition and the risk of NHL. The pooled results suggested that several allergic conditions, including asthma, hay fever, food allergy, and allergic rhinitis, were inversely associated with the risk of NHL (for asthma, pooled $\mathrm{OR}=0.94,95 \% \mathrm{CI} 0.88-0.99$; for hay fever, pooled $\mathrm{OR}=0.72$, 95\% CI 0.64-0.82; for food allergy, pooled $\mathrm{OR}=0.71,95 \%$ CI $0.51-0.98$; for allergic rhinitis, pooled $\mathrm{OR}=0.80,95 \%$ CI 0.73-0.88) (Figure 3 and Table 2). The pooled OR for the association between hives and the risk of NHL was 1.67 (95\% CI 1.37-2.04), indicating that population with hives were at a higher risk of NHL (Table 2). We also assessed the association between allergic conditions and subtypes of NHL, as listed in Table 3. As the pooled results suggested, allergic conditions were inversely associated with both B-cell NHL (pooled OR $=0.74,95 \%$ CI 0.59-0.92) and T-cell NHL (pooled $\mathrm{OR}=0.70,95 \%$ CI 0.52-0.94). Allergic conditions were indicated to be inversely associated with the risk of diffuse large B-cell lymphoma (DLBCL) (pooled OR=0.85, 95\% CI 0.75-0.97), while there was no evidence that allergic conditions were associated with follicular lymphoma or marginal zone lymphoma. The results of subgroup analyses for geographic region are listed in Table 3. Subgroup analyses suggested that heterogeneity could be partially explained by the type of allergic conditions.

\section{Association between allergic conditions and the risk of $\mathrm{HL}$}

Finally, 12 studies comprising $2750 \mathrm{HL}$ cases were included in the analysis of the risk of HL in individuals with allergic conditions. Two of the included studies were designed as cohort study, and the others were case-control studies (seven were population based and three were hospital based). One study enrolled only males, while the other studies assessed the association between allergic conditions and the risk of $\mathrm{HL}$ in both males and females. All the included studies were conducted in North America and European countries.

There was no significant association in case-control studies (pooled OR $=0.96,95 \%$ CI $0.84-1.09)\left(I^{2}=19.4 \%\right.$, $P=0.265$ ) (Figure 4 and Table 1). The results were consistent in population-based case-control studies (pooled $\mathrm{OR}=1.00$, 95\% CI 0.86-1.15) and hospital-based case-control studies 
A Study ID

Population-based case-control

Wang et al (2015)

Rudant et al (2011)

El-Zein et al $(2010)^{23}$

Melbye et al $(2007)^{4}$ case-control

Cozen et al $(2007)^{28}$

Soderberg et al $(2006)^{30}$

Bracci et al (2006) $)^{31}$

Becker et al (2005) ${ }^{33}$

Zhang et al (2004) $)^{34}$

Briggs et al (2002) $)^{37}$

Fabbro-Peray et al (2001) $)^{38}$

Vineis et al $(2000)^{39}$

Holly et al $(1999)^{40}$

Bernstein and Ross $(1992)^{44}$

Subtotal $\left(I^{2}=63.8 \%, P=0.000\right)$

Hospital-based case-control

Dikalioti et al $(2012)^{7}$

Cerhan et al (2011) 22

Ellison-Loschmann et al (2007) $)^{27}$

La Vecchia et al (1992) ${ }^{42}$

Doody et al (1992) ${ }^{43}$

Franceschi et al (1989) ${ }^{45}$

Cartwright et al $(1988)^{46}$

Tielsch et al $(1987)^{47}$

Subtotal $\left(I^{2}=67.1 \%, P=0.002\right)$

Overall $\left(I^{2}=66.7 \%, P=0.000\right)$
Grulich et al (2005)

Becker et al $(2007)^{29}$

OR $(95 \% \mathrm{Cl}) \quad \%$ weight

$0.31(0.15,0.64) \quad 1.36$

$0.86(0.60,1.22) \quad 3.70$

$0.67(0.34,1.32) \quad 1.52$

$0.53(0.39,0.70) \quad 4.48$

$0.90(0.70,1.20) \quad 4.81$

$0.90(0.80,1.00) \quad 7.24$

$0.70(0.60,0.83) \quad 6.48$

$0.80(0.71,0.92) \quad 6.99$

$0.74(0.60,0.90) \quad 5.83$

$1.07(0.89,1.29) \quad 6.11$

$1.00(0.80,1.20) \quad 5.83$

$0.89(0.41,1.93) \quad 1.22$

$0.90(0.70,1.30) \quad 4.25$

$0.82(0.74,0.91) \quad 7.35$

$0.66(0.52,0.85) \quad 5.16$

$0.80(0.73,0.88) \quad 72.34$

$0.50(0.27,0.92) \quad 1.78$

$1.20(0.97,1.48) \quad 5.70$

$0.54(0.36,0.81) \quad 3.18$

$0.89(0.69,1.13) \quad 5.14$

$1.00(0.60,2.10) \quad 1.72$

$0.79(0.41,1.52) \quad 1.60$

$0.96(0.63,1.46) \quad 3.04$

$1.60(1.10,2.40) \quad 3.33$

$0.77(0.45,1.32) \quad 2.17$

$0.90(0.71,1.13) \quad 27.66$

$0.83(0.76,0.91) \quad 100$

OR $(95 \% \mathrm{Cl}) \quad \%$ weight

B Study ID

Prospective cohort Hofmann et al (2015) 11

Helby et al (2015) ${ }^{16}$

Nieters et al (2014) $)^{17}$

Linabery et al (2014) ${ }^{18}$

Erber et al (2009) ${ }^{25}$

Melbye et al $(2007)^{4}$ cohort

Vesterinen et al (1993) ${ }^{41}$

Koshiol et al (2011) 12

Eriksson et al (2005) $)^{32}$

Subtotal $\left(I^{2}=81.3 \%, P=0.000\right)$

Retrospective cohort

Liu et al (2015) ${ }^{10}$

Hemminki et al (2014) ${ }^{20}$

Chen et al (2012) ${ }^{21}$

Soderberg et al $(2004)^{35}$

Subtotal $\left(I^{2}=95.0 \%, P=0.000\right)$

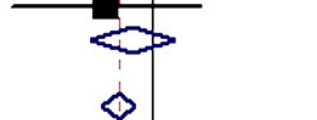

1.5

$0.61(0.42,0.87) \quad 7.51$

$1.58(1.07,2.33) \quad 7.21$

$0.86(0.39,1.93) \quad 3.52$

$0.95(0.75,1.22) \quad 8.99$

$1.10(0.95,1.28) \quad 9.97$

$0.78(0.50,1.21) \quad 6.59$

$0.99(0.77,1.28) \quad 8.86$

$1.40(1.30,1.50) \quad 10.51$

$1.78(0.66,3.88) \quad 3.06$

$1.05(0.86,1.28) \quad 66.21$

$1.04(0.93,1.16) \quad 10.28$

$1.00(0.82,1.22) \quad 9.49$

$4.40(3.00,6.10) \quad 7.62$

$1.30(0.80,2.00) \quad 6.40$

$1.54(0.91,2.58) \quad 33.79$

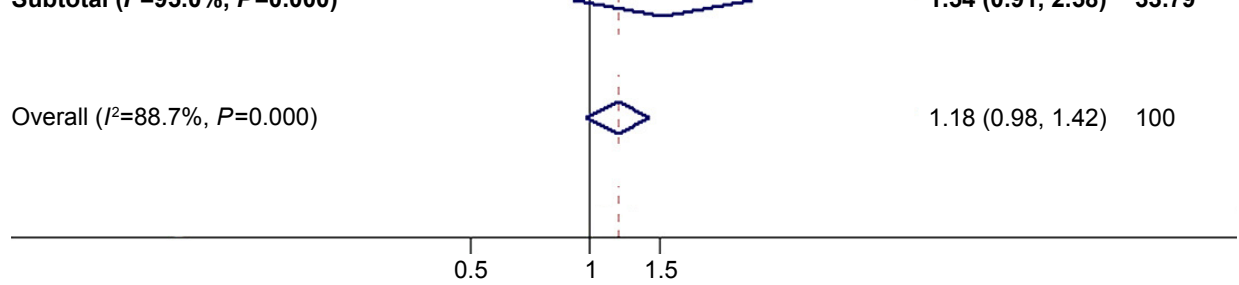

$1.18(0.98,1.42) \quad 100$

Figure 2 Association between history of allergic conditions and the risk of NHL.

Notes: (A) Pooled analysis of case-control studies. (B) Pooled analysis of cohort studies. Weights are from random-effects analysis.

Abbreviations: $\mathrm{Cl}$, confidence interval; $\mathrm{NHL}$, non-Hodgkin's lymphoma; OR, odds ratio. 
Table I Association between history of allergic conditions and the risk of $\mathrm{NHL} / \mathrm{HL}$ according to study design

\begin{tabular}{|c|c|c|c|c|}
\hline \multirow[t]{2}{*}{ Factor } & \multirow{2}{*}{$\begin{array}{l}\text { Number } \\
\text { of studies }\end{array}$} & \multirow{2}{*}{$\begin{array}{l}\text { Pooled OR/RR } \\
(95 \% \mathrm{Cl})\end{array}$} & \multicolumn{2}{|c|}{ Heterogeneity } \\
\hline & & & $I^{2}(\%)$ & $P$-value \\
\hline \multicolumn{5}{|l|}{ NHL } \\
\hline All case-control study & 24 & $0.83(0.76-0.91)$ & 66.7 & $<0.001$ \\
\hline Population based & 15 & $0.80(0.73-0.88)$ & 63.8 & $<0.001$ \\
\hline Hospital based & 9 & $0.90(0.7 \mid-1.13)$ & 67.1 & 0.002 \\
\hline All cohort study & 13 & $1.18(0.98-1.42)$ & 88.7 & $<0.001$ \\
\hline Prospective & 9 & $1.05(0.86-1.28)$ & 81.3 & $<0.001$ \\
\hline Retrospective & 4 & $1.54(0.91-2.58)$ & 95.0 & $<0.001$ \\
\hline $\begin{array}{l}\text { All case-control } \\
\text { and cohort studies }\end{array}$ & 37 & $0.93(0.84-1.04)$ & 87.8 & $<0.001$ \\
\hline \multicolumn{5}{|l|}{ HL } \\
\hline All case-control study & 10 & $0.96(0.84-1.09)$ & 19.4 & 0.265 \\
\hline Population based & 7 & $1.00(0.86-1.15)$ & 34.6 & 0.164 \\
\hline Hospital based & 3 & $0.79(0.58-1.08)$ & 0 & 0.893 \\
\hline All cohort study & 2 & $1.46(0.63-3.38)$ & 58.3 & 0.121 \\
\hline $\begin{array}{l}\text { All case-control and } \\
\text { cohort studies }\end{array}$ & 12 & $0.99(0.88-1.11)$ & 26.5 & 0.184 \\
\hline
\end{tabular}

Note: The OR/RR of individual study was pooled with a random-effects model if there was significant heterogeneity, otherwise a fixed-effects model was used. Abbreviations: $\mathrm{Cl}$, confidence interval; $\mathrm{HL}$, Hodgkin's lymphoma; $\mathrm{NHL}$, non- $\mathrm{HL}$; $\mathrm{OR}$, odds ratio; $\mathrm{RR}$, relative risk.

(pooled OR $=0.79,95 \%$ CI $0.58-1.08$ ) (Figure 4 and Table 1). The pooled OR of cohort studies was 1.46 (95\% CI 0.63-3.38) $\left(I^{2}=58.3 \%, P=0.121\right)$. The pooled analysis of all the 12 case-control and cohort studies represented an OR of 0.99 (95\% CI $0.88-1.11)\left(I^{2}=26.5 \%, P=0.184\right)$, indicating that history of allergic conditions was not significantly associated with the risk of HL.

Stratifying by the type of allergic conditions, an inverse association with the risk of HL was indicated for hay fever (pooled OR $=0.71,95 \%$ CI $0.54-0.93$ ) and food allergy (pooled OR $=0.54,95 \%$ CI 0.33-0.88) (Table 4). We found no significant association for asthma and eczema, as listed in Table 4. Results of subgroup analyses according to geographic region are listed in Table 4.

\section{Publication bias}

Begg's funnel plot and Egger's tests suggested no publication bias in the current study.

\section{Discussion}

Epidemiological studies have suggested possible relationships between allergic conditions and kinds of malignant diseases, while results of those studies were inconsistent. Previous meta-analyses of case-control studies have confirmed a reduction in the risk of NHL in people with several specific allergic conditions, including hay fever and asthma. ${ }^{9,48}$ However, these reports did not include cohort studies, which mostly report a null association. This large-scale meta-analysis included 37 articles on the risk of NHL and a total of 12 studies evaluating the risk of HL. As the pooled studies suggested, history of any allergic condition was significantly associated with the risk of NHL in casecontrol studies (pooled OR $=0.83,95 \%$ CI 0.76-0.91) but not in cohort studies (pooled OR $=1.18,95 \%$ CI 0.98-1.42). Stratifying by different allergic conditions, we observed an inverse association between hay fever, food allergy, and allergic rhinitis and the risk of NHL, while hives were positively associated with the risk of NHL. No significant association between allergic conditions and the risk of HL was suggested in case-control studies (pooled OR $=0.96,95 \%$ CI 0.84-1.09) or cohort studies (pooled OR $=1.46,95 \%$ CI $0.63-3.38$ ). However, a reduction in the risk of HL was suggested in individuals with hay fever and food allergy.

In the analysis of the relationship between allergic conditions and the risk of NHL, a significant difference was observed between cohort studies and case-control studies. Though the number of NHL cases in some of the cohort studies was limited, a total of 13 cohort studies enrolling 4452 NHL cases were included in the current analysis, which increased the power to assess the association. Some of the included cohort studies were retrospective and based on registers using national data as external comparison, while studies adopting internal controls might estimate the risk more accurately.$^{49}$ However, null association was suggested in both prospective cohort studies (pooled OR $=1.05,95 \%$ CI 0.86 1.28) and retrospective register-based cohort studies (pooled $\mathrm{OR}=1.54,95 \%$ CI $0.91-2.58$ ). The inconsistency between cohort studies and case-control studies might be partially due to the reliance on self-report of allergic conditions, which is prone to recall bias and less objective. ${ }^{12}$ Moreover, patients with NHL might be associated with a reduced immunoglobulin reactivity; thus, these NHL cases might have a reduced immune response and allergic responses. ${ }^{4,50}$ The negative association between allergic conditions and the risk of NHL might be explained by reverse causality. A pooled analysis of 13 case-control studies assessed the association between atopic diseases and the risk of NHL, suggesting a modest reduction in the risk of NHL in atopic disease. ${ }^{9}$ Another pooled analysis of 20 case-control studies from the International Lymphoma Epidemiology Consortium (InterLymph) indicated that some allergic conditions, such as asthma and hay fever, were negatively associated with the risk of NHL..$^{48}$ However, no pooled analysis of cohort studies has been conducted. Cohort studies are more adept at evaluating causal relationships, and evidence from cohort studies is usually considered stronger than case-control studies. Thus, more 

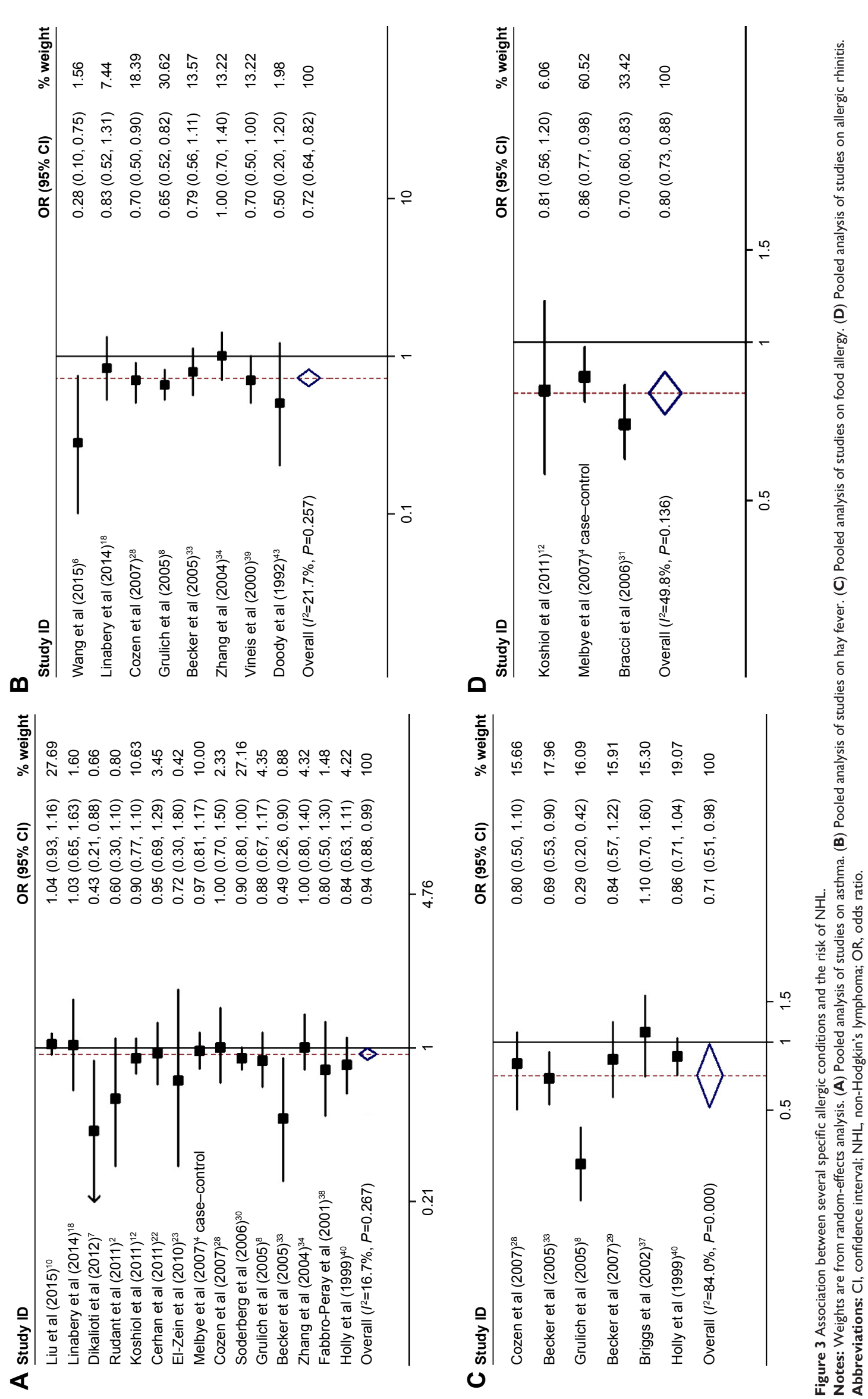
Table 2 Association between history of specific allergic conditions and the risk of $\mathrm{NHL}$

\begin{tabular}{|c|c|c|c|c|}
\hline \multirow{2}{*}{$\begin{array}{l}\text { Allergic } \\
\text { conditions }\end{array}$} & \multirow{2}{*}{$\begin{array}{l}\text { Number } \\
\text { of studies }\end{array}$} & \multirow{2}{*}{$\begin{array}{l}\text { Pooled OR/RR } \\
(95 \% \mathrm{Cl})\end{array}$} & \multicolumn{2}{|c|}{ Heterogeneity } \\
\hline & & & $I^{2}(\%)$ & $P$-value \\
\hline Asthma & 15 & $0.94(0.88-0.99)$ & 16.7 & 0.267 \\
\hline Hay fever & 8 & $0.72(0.64-0.82)$ & 21.7 & 0.257 \\
\hline Food allergy & 6 & $0.7 \mid(0.5 I-0.98)$ & 84.0 & $<0.001$ \\
\hline Allergic rhinitis & 3 & $0.80(0.73-0.88)$ & 49.8 & 0.136 \\
\hline Dust allergy & 3 & $0.85(0.73-1.00)$ & 0 & 0.614 \\
\hline Eczema & 15 & $0.99(0.8|-| .2 I)$ & 82.8 & $<0.001$ \\
\hline Hives & 4 & $1.67(1.37-2.04)$ & 48.2 & 0.122 \\
\hline IgE level & 4 & $0.86(0.49-1.49)$ & 84.5 & $<0.001$ \\
\hline Insect allergy & 2 & $0.94(0.64-1.37)$ & 0 & 0.682 \\
\hline Animal allergy & 3 & $0.83(0.58-1.17)$ & 58.5 & 0.088 \\
\hline Medicine allergy & 5 & $1.06(0.89-1.25)$ & 64.6 & 0.023 \\
\hline
\end{tabular}

Note: The OR/RR of individual study was pooled with a random-effects model if there was significant heterogeneity, otherwise a fixed-effects model was used. Abbreviations: $\mathrm{Cl}$, confidence interval; NHL, non-Hodgkin's lymphoma; OR, odds ratio; $R R$, relative risk.

cohort studies, especially prospective cohort studies, are warranted to clarify this question.

There has long been interest in the relationship between allergic conditions and the risk of malignancy. Previous studies have indicated that the association between allergic conditions and the risk of cancer was different according to cancer site and types of allergic conditions. A meta-analysis of 10 case-control studies suggested a reduction in the risk of pancreatic cancer in population with allergic conditions. ${ }^{51}$ Further analyses demonstrated that hay fever and allergy to animals, but not asthma or other allergies, reduced the risk of pancreatic cancer. ${ }^{51}$ Previous meta-analysis has also indicated an association between allergic conditions and

Table 3 Association between history of allergic conditions and the risk of $\mathrm{NHL}$ according to the type of $\mathrm{NHL}$ and geographic region

\begin{tabular}{|c|c|c|c|c|}
\hline \multirow[t]{2}{*}{ Factor } & \multirow{2}{*}{$\begin{array}{l}\text { Number } \\
\text { of studies }\end{array}$} & \multirow{2}{*}{$\begin{array}{l}\text { Pooled OR/RR } \\
(95 \% \mathrm{Cl})\end{array}$} & \multicolumn{2}{|c|}{ Heterogeneity } \\
\hline & & & $I^{2}(\%)$ & $P$-value \\
\hline \multicolumn{5}{|l|}{ NHL type } \\
\hline B-cell NHL & 8 & $0.74(0.59-0.92)$ & 73.3 & $<0.001$ \\
\hline T-cell NHL & 3 & $0.70(0.52-0.94)$ & 0 & 0.520 \\
\hline DLBCL & 8 & $0.85(0.75-0.97)$ & 0 & 0.791 \\
\hline FL & 9 & $0.94(0.77-1.15)$ & 51.1 & 0.037 \\
\hline MZL & 2 & $0.56(0.27-1.16)$ & 29.5 & 0.234 \\
\hline LPL & 2 & $0.38(0.14-1.04)$ & 0 & 0.419 \\
\hline \multicolumn{5}{|c|}{ Geographic region } \\
\hline USA and & 15 & $0.87(0.74-1.03)$ & 90.6 & $<0.001$ \\
\hline \multicolumn{5}{|l|}{ Canada } \\
\hline Europe & 20 & $0.91(0.8 \mathrm{I}-1.02)$ & 65.3 & $<0.00$ I \\
\hline Others & 2 & $1.86(0.35-9.89)$ & 98.7 & $<0.001$ \\
\hline
\end{tabular}

Note: The OR/RR of individual study was pooled with a random-effects model if there was significant heterogeneity, otherwise a fixed-effects model was used.

Abbreviations: $\mathrm{Cl}$, confidence interval; $\mathrm{DLBCL}$, diffuse large B-cell lymphoma; FL, follicular lymphoma; LPL, lymphoplasmacytic lymphoma; MZL, marginal zone lymphoma; NHL, non-Hodgkin's lymphoma; OR, odds ratio; RR, relative risk. the risk of head and neck cancers. ${ }^{52}$ In the present analysis, we observed a negative association with the risk of NHL for several allergic conditions, including hay fever, asthma, food allergy, and allergic rhinitis. An increased risk of NHL for hives was also suggested. However, the associations were mainly found in case-control studies but not in cohort studies. Few studies have been conducted to explore the risk of NHL in relation to allergic conditions according to race/ethnicity. Erber et $\mathrm{al}^{25}$ investigated the association between common immune-related factors and the risk of NHL, suggesting that the association was limited to certain ethnic groups. Another study also supported a role for racerelated differences in genes regulating immune/inflammatory response. ${ }^{12}$ Our pooled analysis also demonstrated that hay fever (pooled OR $=0.71,95 \%$ CI $0.54-0.93$ ) and food allergy (pooled OR $=0.54,95 \%$ CI $0.33-0.88$ ) were significantly associated with the risk of HL, though null association was observed for any allergic condition.

There has been plenty of research investigating the role of allergic conditions in malignancy, while the mechanisms remain unclear. According to the "cancer immunosurveillance hypothesis", people with allergic conditions may have an activated response of immune system, which promotes the ability to eradicate premalignant cells and, thus, reduced the risk of lymphomas..$^{53}$ Besides, Immunoglobulin E (IgE) can bind to cell surface IgE receptors, CD23 and FceRI, which engage several types of antitumor effector cells. ${ }^{54}$ Moreover, other blood cells associated with allergic diseases, such as eosinophils and mast cells, have been indicated to play a role in eliminating tumor cells. ${ }^{54,55}$ In contrast, for individuals with allergic conditions, antigenic stimulation may lead to a chronic inflammation and stimulate cell growth, which may increase the risk of malignancies. ${ }^{5}$ The mechanisms of allergic conditions on NHL and HL are complicated and unclear; thus, further studies are warranted to explore this issue.

One of the advantages of the current study is the large sample size, which increased the statistical power to evaluate the association between allergic conditions and the risk of NHL. However, there are also some limitations in this study. First, though most of the studies involved in this analysis were adjusted for other known risk factors of NHL or HL, the confounders might be different across the included studies and it is possible that the control of confounders is inadequate. This may lead to exaggeration or underestimation in the risk estimates in the current study. Second, most of the included studies used self-report for the diagnosis of allergic conditions, which might not be accurate enough. In addition, few studies reported the risk of lymphoma in 


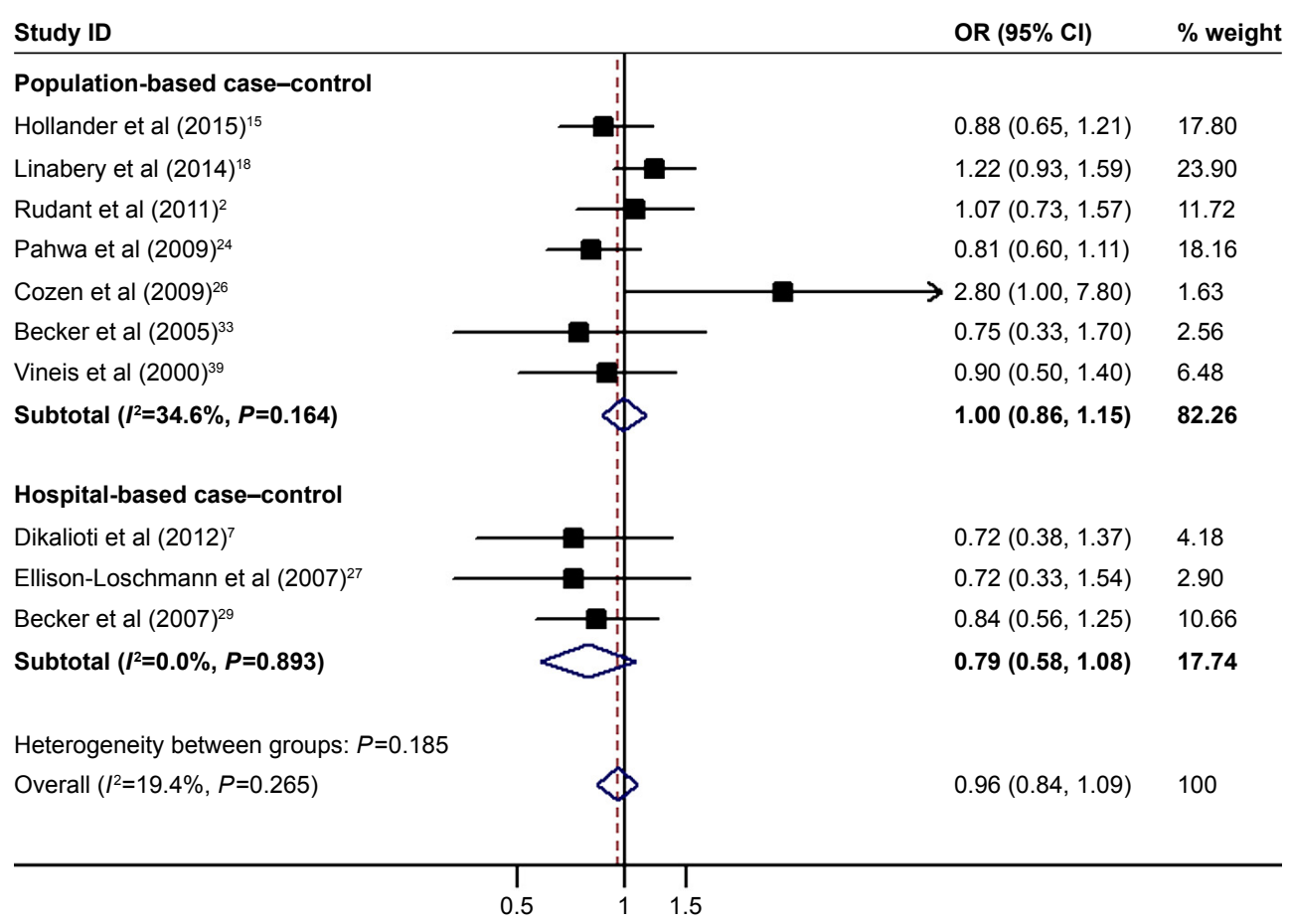

Figure 4 Association between history of allergic conditions and the risk of HL.

Abbreviations: $\mathrm{Cl}$, confidence interval; $\mathrm{HL}$, Hodgkin's lymphoma; OR, odds ratio.

multiple allergic conditions, which may need further evaluation. Finally, most of the included studies were conducted in Europe and North America and the participants enrolled were mainly Caucasian population. Thus, the pooled results should be interpreted with caution for other population.

\section{Conclusion}

History of any allergic condition was not significantly associated with the risk of NHL or HL. Several specific allergic conditions, including asthma, hay fever, food allergy, and

Table 4 Association between history of allergic conditions and the risk of $\mathrm{HL}$ according to the type of allergic conditions and geographic region

\begin{tabular}{|c|c|c|c|c|}
\hline \multirow[t]{2}{*}{ Factor } & \multirow{2}{*}{$\begin{array}{l}\text { Number } \\
\text { of studies }\end{array}$} & \multirow{2}{*}{$\begin{array}{l}\text { Pooled OR/RR } \\
(95 \% \mathrm{Cl})\end{array}$} & \multicolumn{2}{|c|}{ Heterogeneity } \\
\hline & & & $\overline{I^{2}(\%)}$ & $P$-value \\
\hline \multicolumn{5}{|c|}{ Allergic conditions } \\
\hline Hay fever & 3 & $0.71(0.54-0.93)$ & 57.5 & 0.095 \\
\hline Food allergy & 2 & $0.54(0.33-0.88)$ & 0 & 0.916 \\
\hline Asthma & 7 & $0.99(0.83-1.18)$ & 0 & 0.693 \\
\hline Eczema & 4 & $1.21(0.80-1.83)$ & 56.1 & 0.077 \\
\hline \multicolumn{5}{|c|}{ Geographic region } \\
\hline USA and & 3 & $1.16(0.73-1.83)$ & 73.1 & 0.024 \\
\hline \multicolumn{5}{|l|}{ Canada } \\
\hline Europe & 9 & $0.95(0.82-1.10)$ & 0 & 0.563 \\
\hline
\end{tabular}

Note: The OR/RR of individual study was pooled with a random-effects model if there was significant heterogeneity, otherwise a fixed-effects model was used. Abbreviations: $\mathrm{Cl}$, confidence interval; $\mathrm{HL}$, Hodgkin's lymphoma; OR, odds ratio; $\mathrm{RR}$, relative risk. allergic rhinitis, might be associated with a reduced risk of NHL, while individuals with hay fever or food allergy may have a reduced risk of HL. Further large-scale prospective cohort studies are warranted to clarify the association between history of allergic diseases and the risk of lymphoma.

\section{Acknowledgments}

We thank Dr Peiwei Li for revising the article. English language copy editing has been performed. The abstract of this article has been submitted to ESMO ASIA 2016 Congress, Singapore and published previously (Ann Oncol [2016] 27 [suppl_9]: mdw586.016).

\section{Disclosure}

The authors report no conflicts of interest in this work.

\section{References}

1. Ferlay J, Shin HR, Bray F, Forman D, Mathers C, Parkin DM. Estimates of worldwide burden of cancer in 2008: GLOBOCAN 2008. Int J Cancer. 2010;127(12):2893-2917.

2. Rudant J, Orsi L, Monnereau A, et al. Childhood Hodgkin's lymphoma, non-Hodgkin's lymphoma and factors related to the immune system: the Escale Study (SFCE). Int J Cancer. 2011;129(9):2236-2247.

3. Grulich AE, Vajdic CM, Cozen W. Altered immunity as a risk factor for non-Hodgkin lymphoma. Cancer Epidemiol Biomarkers Prev. 2007; 16(3):405-408

4. Melbye M, Smedby KE, Lehtinen T, et al. Atopy and risk of non-Hodgkin lymphoma. J Natl Cancer Inst. 2007;99(2):158-166.

5. Wang $\mathrm{H}$, Diepgen TL. Is atopy a protective or a risk factor for cancer? A review of epidemiological studies. Allergy. 2005;60(9):1098-1111. 
6. Wang J, Mack TM, Hamilton AS, et al. Common immune-related exposures/conditions and risk of non-Hodgkin lymphoma: a case-control study of disease-discordant twin pairs. Am J Epidemiol. 2015;182(5): 417-425.

7. Dikalioti SK, Chang ET, Dessypris N, et al. Allergy-associated symptoms in relation to childhood non-Hodgkin's as contrasted to Hodgkin's lymphomas: a case-control study in Greece and meta-analysis. Eur $J$ Cancer. 2012;48(12):1860-1866.

8. Grulich AE, Vajdic CM, Kaldor JM, et al. Birth order, atopy, and risk of non-Hodgkin lymphoma. J Natl Cancer Inst. 2005;97(8):587-594.

9. Vajdic CM, Falster MO, de Sanjose S, et al. Atopic disease and risk of non-Hodgkin lymphoma: an InterLymph pooled analysis. Cancer Res. 2009;69(16):6482-6489.

10. Liu X, Hemminki K, Forsti A, Sundquist J, Sundquist K, Ji J. Cancer risk and mortality in asthma patients: a Swedish national cohort study. Acta Oncol. 2015;54(8):1120-1127.

11. Hofmann JN, Hoppin JA, Lynch CF, et al. Farm characteristics, allergy symptoms, and risk of non-Hodgkin lymphoid neoplasms in the agricultural health study. Cancer Epidemiol Biomarkers Prev. 2015;24(3):587-594.

12. Koshiol J, Lam TK, Gridley G, Check D, Brown LM, Landgren O. Racial differences in chronic immune stimulatory conditions and risk of non-Hodgkin's lymphoma in veterans from the United States. J Clin Oncol. 2011;29(4):378-385.

13. Moher D, Liberati A, Tetzlaff J, Altman DG, Group P. Preferred reporting items for systematic reviews and meta-analyses: the PRISMA statement. PLoS Med. 2009;6(7):e1000097.

14. Higgins JP, Thompson SG. Quantifying heterogeneity in a metaanalysis. Stat Med. 2002;21(11):1539-1558.

15. Hollander P, Rostgaard K, Smedby KE, et al. Autoimmune and atopic disorders and risk of classical Hodgkin lymphoma. Am J Epidemiol. 2015;182(7):624-632.

16. Helby J, Bojesen SE, Nielsen SF, Nordestgaard BG. IgE and risk of cancer in 37747 individuals from the general population. Ann Oncol. 2015;26(8):1784-1790.

17. Nieters A, Luczynska A, Becker S, et al. Prediagnostic immunoglobulin E levels and risk of chronic lymphocytic leukemia, other lymphomas and multiple myeloma-results of the European Prospective Investigation into Cancer and Nutrition. Carcinogenesis. 2014;35(12) 2716-2722.

18. Linabery AM, Prizment AE, Anderson KE, Cerhan JR, Poynter JN, Ross JA. Allergic diseases and risk of hematopoietic malignancies in a cohort of postmenopausal women: a report from the Iowa Women's Health Study. Cancer Epidemiol Biomarkers Prev. 2014;23(9):1903-1912.

19. Linabery AM, Erhardt EB, Fonstad RK, et al. Infectious, autoimmune and allergic diseases and risk of Hodgkin lymphoma in children and adolescents: a Children's Oncology Group study. Int J Cancer. 2014; 135(6):1454-1469

20. Hemminki K, Forsti A, Fallah M, Sundquist J, Sundquist K, Ji J. Risk of cancer in patients with medically diagnosed hay fever or allergic rhinitis. Int J Cancer. 2014;135(10):2397-2403.

21. Chen YJ, Wu CY, Shen JL, Chen TT, Chang YT. Cancer risk in patients with chronic urticaria: a population-based cohort study. Arch Dermatol. 2012;148(1):103-108.

22. Cerhan JR, Fredericksen ZS, Wang AH, et al. Design and validity of a clinic-based case-control study on the molecular epidemiology of lymphoma. Int J Mol Epidemiol Genet. 2011;2(2):95-113.

23. El-Zein M, Parent ME, Ka K, Siemiatycki J, St-Pierre Y, Rousseau MC. History of asthma or eczema and cancer risk among men: a populationbased case-control study in Montreal, Quebec, Canada. Ann Allergy Asthma Immunol. 2010;104(5):378-384.

24. Pahwa P, Karunanayake CP, Spinelli JJ, Dosman JA, McDuffie HH. Ethnicity and incidence of Hodgkin lymphoma in Canadian population. BMC Cancer. 2009;9:141.

25. Erber E, Lim U, Maskarinec G, Kolonel LN. Common immune-related risk factors and incident non-Hodgkin lymphoma: the multiethnic cohort. Int J Cancer. 2009;125(6):1440-1445.
26. Cozen W, Hamilton AS, Zhao P, et al. A protective role for early oral exposures in the etiology of young adult Hodgkin lymphoma. Blood. 2009; 114(19):4014-4020.

27. Ellison-Loschmann L, Benavente Y, Douwes J, et al. Immunoglobulin E levels and risk of lymphoma in a case-control study in Spain. Cancer Epidemiol Biomarkers Prev. 2007;16(7):1492-1498.

28. Cozen W, Cerhan JR, Martinez-Maza O, et al. The effect of atopy, childhood crowding, and other immune-related factors on non-Hodgkin lymphoma risk. Cancer Causes Control. 2007;18(8):821-831.

29. Becker N, de Sanjose S, Nieters A, et al. Birth order, allergies and lymphoma risk: results of the European collaborative research project Epilymph. Leuk Res. 2007;31(10):1365-1372.

30. Soderberg KC, Jonsson F, Winqvist O, Hagmar L, Feychting M. Autoimmune diseases, asthma and risk of haematological malignancies: a nationwide case-control study in Sweden. Eur J Cancer. 2006;42(17): 3028-3033.

31. Bracci PM, Dalvi TB, Holly EA. Residential history, family characteristics and non-Hodgkin lymphoma, a population-based case-control study in the San Francisco Bay Area. Cancer Epidemiol Biomarkers Prev. 2006;15(7):1287-1294.

32. Eriksson NE, Mikoczy Z, Hagmar L. Cancer incidence in 13811 patients skin tested for allergy. J Investig Allergol Clin Immunol. 2005;15(3): 161-166.

33. Becker N, Deeg E, Rudiger T, Nieters A. Medical history and risk for lymphoma: results of a population-based case-control study in Germany. Eur J Cancer. 2005;41(1):133-142.

34. Zhang Y, Holford TR, Leaderer B, et al. Prior medical conditions and medication use and risk of non-Hodgkin lymphoma in Connecticut United States women. Cancer Causes Control. 2004;15(4) 419-428.

35. Soderberg KC, Hagmar L, Schwartzbaum J, Feychting M. Allergic conditions and risk of hematological malignancies in adults: a cohort study. BMC Public Health. 2004;4:51.

36. Holly EA, Bracci PM. Population-based study of non-Hodgkin lymphoma, histology, and medical history among human immunodeficiency virus-negative participants in San Francisco. Am J Epidemiol. 2003; 158(4):316-327.

37. Briggs NC, Levine RS, Brann EA. Allergies and risk of non-Hodgkin's lymphoma by subtype. Cancer Epidemiol Biomarkers Prev. 2002; 11(4):401-407.

38. Fabbro-Peray P, Daures JP, Rossi JF. Environmental risk factors for non-Hodgkin's lymphoma: a population-based case-control study in Languedoc-Roussillon, France. Cancer Causes Control. 2001;12(3): 201-212.

39. Vineis P, Crosignani P, Sacerdote C, et al. Haematopoietic cancer and medical history: a multicentre case control study. J Epidemiol Community Health. 2000;54(6):431-436.

40. Holly EA, Lele C, Bracci PM, McGrath MS. Case-control study of non-Hodgkin's lymphoma among women and heterosexual men in the San Francisco Bay Area, California. Am J Epidemiol. 1999;150(4): 375-389.

41. Vesterinen E, Pukkala E, Timonen T, Aromaa A. Cancer incidence among 78,000 asthmatic patients. Int J Epidemiol. 1993;22(6): 976-982.

42. La Vecchia C, Negri E, Franceschi S. Medical history and the risk of non-Hodgkin's lymphomas. Cancer Epidemiol Biomarkers Prev. 1992;1(7):533-536.

43. Doody MM, Linet MS, Glass AG, et al. Leukemia, lymphoma, and multiple myeloma following selected medical conditions. Cancer Causes Control. 1992;3(5):449-456.

44. Bernstein L, Ross RK. Prior medication use and health history as risk factors for non-Hodgkin's lymphoma: preliminary results from a casecontrol study in Los Angeles County. Cancer Res. 1992;52(19 suppl): $5510 \mathrm{~s}-5515 \mathrm{~s}$.

45. Franceschi S, Serraino D, Bidoli E, et al. The epidemiology of nonHodgkin's lymphoma in the north-east of Italy: a hospital-based casecontrol study. Leuk Res. 1989;13(6):465-472. 
46. Cartwright RA, McKinney PA, O’Brien C, et al. Non-Hodgkin's lymphoma: case control epidemiological study in Yorkshire. Leuk Res. 1988; 12(1):81-88.

47. Tielsch JM, Linet MS, Szklo M. Acquired disorders affecting the immune system and non-Hodgkin's lymphoma. Prev Med. 1987;16(1): 96-106.

48. Morton LM, Slager SL, Cerhan JR, et al. Etiologic heterogeneity among non-Hodgkin lymphoma subtypes: the InterLymph NonHodgkin Lymphoma Subtypes Project. J Natl Cancer Inst Monogr. 2014;2014(48):130-144.

49. Card TR, Solaymani-Dodaran M, Hubbard R, Logan RF, West J. Is an internal comparison better than using national data when estimating mortality in longitudinal studies? J Epidemiol Community Health. 2006; 60(9):819-821.

50. Grulich AE, Vajdic CM, Riminton S, Hughes AM, Kricker A, Armstrong BK. Re: atopy and risk of non-Hodgkin lymphoma. J Natl Cancer Inst. 2007;99(18):1417.
51. Olson SH, Hsu M, Satagopan JM, et al. Allergies and risk of pancreatic cancer: a pooled analysis from the Pancreatic Cancer Case-Control Consortium. Am J Epidemiol. 2013;178(5):691-700.

52. Hsiao JR, Ou CY, Lo HI, et al. Allergies and risk of head and neck cancer: an original study plus meta-analysis. PLoS One. 2013;8(2):e55138.

53. Markiewicz MA, Gajewski TF. The immune system as anti-tumor sentinel: molecular requirements for an anti-tumor immune response. Crit Rev Oncog. 1999;10(3):247-260.

54. Jensen-Jarolim E, Achatz G, Turner MC, et al. AllergoOncology: the role of IgE-mediated allergy in cancer. Allergy. 2008;63(10):1255-1266.

55. Strik MC, de Koning PJ, Kleijmeer MJ, et al. Human mast cells produce and release the cytotoxic lymphocyte associated protease granzyme B upon activation. Mol Immunol. 2007;44(14):3462-3472.
OncoTargets and Therapy

\section{Publish your work in this journal}

OncoTargets and Therapy is an international, peer-reviewed, open access journal focusing on the pathological basis of all cancers, potential targets for therapy and treatment protocols employed to improve the management of cancer patients. The journal also focuses on the impact of management programs and new therapeutic agents and protocols on

\section{Dovepress}

patient perspectives such as quality of life, adherence and satisfaction The manuscript management system is completely online and includes a very quick and fair peer-review system, which is all easy to use. Visit http://www.dovepress.com/testimonials.php to read real quotes from published authors. 